
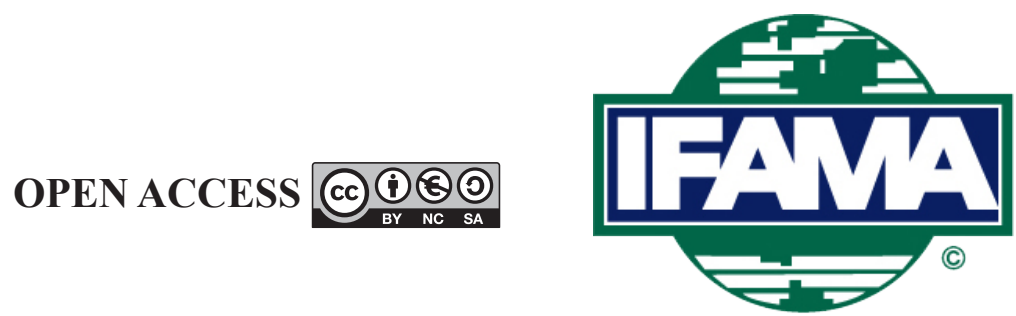

International Food and Agribusiness Management Review

Volume 24, Issue 1, 2021; DOI: 10.22434/IFAMR2020.0001

Received: 1 January 2020 / Accepted: 17 October 2020

\title{
Understanding the job-hopping syndrome among millennial employees in the U.S. food and agribusiness sector: a national survey \\ RESEARCH ARTICLE
}

\author{
Iuliia Tetteh ${ }^{\circledR a}$, Aslihan Spaulding ${ }^{\mathrm{b}}$ and Marina Ptukhina ${ }^{\mathrm{c}}$ \\ ${ }^{a}$ Assistant Professor of Agribusiness, ${ }^{b}$ Professor of Agribusiness, Department of Agriculture, \\ Illinois State University, 134 Ropp Agriculture Building, Campus Box 5020, Normal, IL 61790-5020, USA \\ ${ }^{c}$ Assistant Professor, Department of Mathematics and Statistics, \\ Whitman College, 345 Boyer Ave, Walla Walla, WA 99362, USA
}

\begin{abstract}
A company's ability to retain its employees is one of the pillars of long-term success for any business. For this reason, employee retention and employment continuity have been topics of interest among researchers in business, human capital and psychology fields. By 2025, millennials will constitute approximately $40 \%$ of the U.S. workforce. The existing research suggests that $60 \%$ of millennial employees will leave their employer within three years from their start date imposing significant costs on the company to re-hire and train new employees. These challenges can be even more significant in the U.S. food and agribusiness sector, where a growing global demand for food and fiber increases demand for talent. Therefore, this study uses a national-level survey of millennial employees who work in the U.S. food and agribusiness sector to: (1) explore the frequency of job-hopping; (2) identify job-related factors influencing their decision to stay with their current employer; and (3) evaluate how these factors impact millennial employees' frequency of job-hopping. The findings indicate that the job-hopping is indeed observed in the U.S. food and agribusiness sector but to a lesser degree compared to non-agriculture sectors. The number one reason for leaving or considering leaving their current employer was the lack of opportunities for career growth and advancement. These findings show that employers need to focus on meeting the employees' not only short-term but also long-term career goals, as well as work-life balance, relationship with management, health care benefits to increase employment continuity and reduce job-hopping.
\end{abstract}

Keywords: millennial employees, job-hopping, work-life balance, employee satisfaction, professional development and growth

JEL code: J10, M1, Q010

\footnotetext{
${ }^{\mathbb{\Phi}}$ Corresponding author: iproto1@ilstu.edu
} 


\section{Introduction}

Employee retention and continuity of employment have always been topics of interested among researchers in business, human capital and psychology fields since the ability to retain employees is one of the pillars of the long-term success for any business. Recent research suggests that by 2025 , millennials will constitute approximately $40 \%$ of the U.S. workforce (Asghar, 2014). In addition, studies on consumer preferences and trend forecasting show that millennials have a very distinct set of beliefs, career expectations, and motivations (Asghar, 2014). For example, compared to their predecessors, millennials demand a greater life-work balance, a more flexible schedule, and a faster career progression. Another key difference identified between the millennial workforce and their predecessors is retention rate: only $18 \%$ of surveyed millennials planned to stay with the same employer long term, and $60 \%$ of millennials left their employer within three years from their start date (PwC, 2011; Schawbel, 2013). These finding show that job-hopping imposes significant costs on companies to re-hire and train new employees (Schawbel, 2013).

These challenges can be even more significant in the agribusiness industry, where a growing global demand for food and fiber increases demand for talent. Only $61 \%$ of the expected 57,900 average annual job openings will be filled between 2015 and 2020 (Goecher et al., 2015). The need for talent in agriculture coupled with the changing career expectations of the millennial generation create a greater uncertainty for agricultural employers, and thus talent acquisition and retention in the agribusiness field are likely to become more challenging. Several studies have looked at the millennial phenomenon in other sectors, but none of them has studied the food and agribusiness sector. This study uses a national-level survey of millennial employees in the U.S. food and agribusiness sector to: (1) explore the frequency of job-hopping; (2) identify job-related factors influencing their decisions to stay with their current employer; and (3) evaluate how these job-related and demographic factors impact millennial employees' frequency of job-hopping.

\section{Background}

Demographers generally define the millennial generation as the segment of population born between 1980 and 2000 (Federal Reserve Bank of Atlanta, 2014). Research focused on millennial consumer preferences and trend forecasting shows that millennials have a distinct and iconoclastic set of beliefs, career expectations, and motivations (Asghar, 2014). Millennial demographics differ significantly from their predecessors: they are more educated (23\% have at least a bachelor's degree), speak more languages (65\% speak more than one language) and are more ethnically diverse (19\% Hispanic, 15\% African-American and 5\% Asian (Nielsen, 2014). As a workforce, millennials demand greater life-work balance, a more flexible schedule, more frequent feedback, and faster career progression. On the top of the millennial work wish-list are relationships with peers, opportunity for advancement, and regular training opportunities (McCrindle, 2016). They are also very technology literate, are accustomed to being connected at any time regardless of their location, and do not tolerate the restrictions imposed by the lack of technology (Mitchell, n.d.). For example, 38\% of millennial employees were frustrated when they wasted time searching for documents (compared to $28 \%$ of the total sample base), and 33\% of them lost patience when figuring out who had specific information about a project or a task (compared to $17 \%$ of the total sample base) (Huddle, 2013). These findings confirm not only that millennials have different long-term career expectations, but that they also have different short-term work needs than their predecessors.

Retention rates of the millennial generation are also different from previous generations. Recent research showed that $60 \%$ of millennials left their employer within three years from their start date (Schawbel, 2013). The results of an international survey showed that only $18 \%$ of surveyed millennials planned to stay with the same employer over the long term $(\mathrm{PwC}, 2011)$. A different survey found that a third of respondents lost $15 \%$ of millennial employees within the first year, and $10 \%$ of the lost talent went to their competitors (Schawbel, 2013). Such low retention rates impose explicit (e.g. the costs associated with recruiting a new employee) and implicit costs (e.g. lowered employee productivity due to a higher workload) on the firm (Schawbel, 2013). 
The U.S. food and agribusiness sector is not an exception: in addition to the potential presence of jobhopping, the sector is also facing a higher demand for talent as the growing global demand for food and fiber increases. According to the joint USDA-Purdue report on Employment Opportunities for College Graduates in Food, Agriculture, Renewable Natural Resources and the Environment, only 61\% of the expected 57,900 average annual openings in the food and agribusiness sector was expected to be filled between 2015 and 2020 (Goecher et al., 2015). Therefore, a growing demand for talent in agriculture combined with millennial characteristics and career expectations create even greater challenges for agricultural employers to acquire and retain agricultural employees.

Several studies have looked at the changing preferences of the millennial employees, their incentives to stay with or leave their current employer, and most valued compensation benefits (Deloitte, 2015; Global Prairie and YI Advisors, 2015; Huddle, 2013; Kronos, 2016; Nielsen, 2014; Schawbel, 2013). These studies are informative for employers; however, none of them focused on the millennial phenomenon in the food and agribusiness sector specifically. Australian HR consulting firms raised the importance of this issue for the agribusiness industry but based their concerns off the survey work conducted in the non-agriculture sectors (Agricultural Appointments, 2015). AgCareers.com, the leading on-line job board for the food and agribusiness sector, surveyed agribusiness employees to understand their motivations to leave a current employer and their attitudes towards compensation packages (AgCareers.com, 2013, 2014). Their analysis, however, did not solely reflect the opinions of millennials. Finally, a national-level research project conducted by Global Prairie (a global marketing firm) and YI Advisors (a social impact firm) found that millennials pursuing agricultural degrees or entering the agricultural field had great interest in remaining in and improving the food and agribusiness sector; unfortunately, the conclusions are limited in scope due to selection bias (i.e. the study targeted only highly-motivated individuals who wanted to make a difference in the industry) (Global Prairie and YI Advisors, 2015). Therefore, there is an urgent need for a broader understanding of the phenomenon of job-hopping among the millennial employees in the U.S. food and agribusiness sector.

\subsection{Other factors potentially influencing millennial employees'job-hopping behavior}

The popular press discussions and opinions articles tend to use the culture shifts and stereotypes about behaviors and preferences of millennials to explain the differences in outcomes (e.g. retention rates in the workplace) we observe between them and other generational groups. For example, millennial employees are often described as impatient and entitled individuals, and often these characteristics alone are used to draw conclusions about their inability to hold on to the same job. The limitation of this approach is that it does not account for any macroeconomic and equity trends (e.g. generational differences in asset ownership, debt accumulation and wealth creation), as well as behavioral and attitude changes across life span and between generations. Millennials are facing such social-economic phenomena as increasing cost of living, rising health care costs, growing student debt and slow wealth accumulation which did not have such a widespread impact on previous generations. Thus, failure to discuss economic and societal factors will provide a partial, not a complete view of this issue. Although this paper does not capture these factors directly in its methodology, it is critical to draw attention to these two groups of potential factors that might influence the job-hopping behavior of millennials in the workforce.

In addition to job satisfaction, alignment of beliefs with employers and other factors, financial concerns can also affect the employment continuity of an individual. For example, an individual who carries a lot of debt and has no financial cushion will be more likely to accept any job and will not be able to afford to keep looking for a better fit or career opportunity or may switch the job quickly if a better financial compensation is offered regardless of their job satisfaction with current employer. Figure 1 and Table 1 provide the relevant data on millennials' financial well-being compared to other generations and age groups. Figure 1 shows the trend of wealth ownership by various age groups over time (from 1990 until 2019). It demonstrates that at any point in time, older individuals own a larger share of the U.S. wealth which follows a traditional lifecycle consumption model theory. 


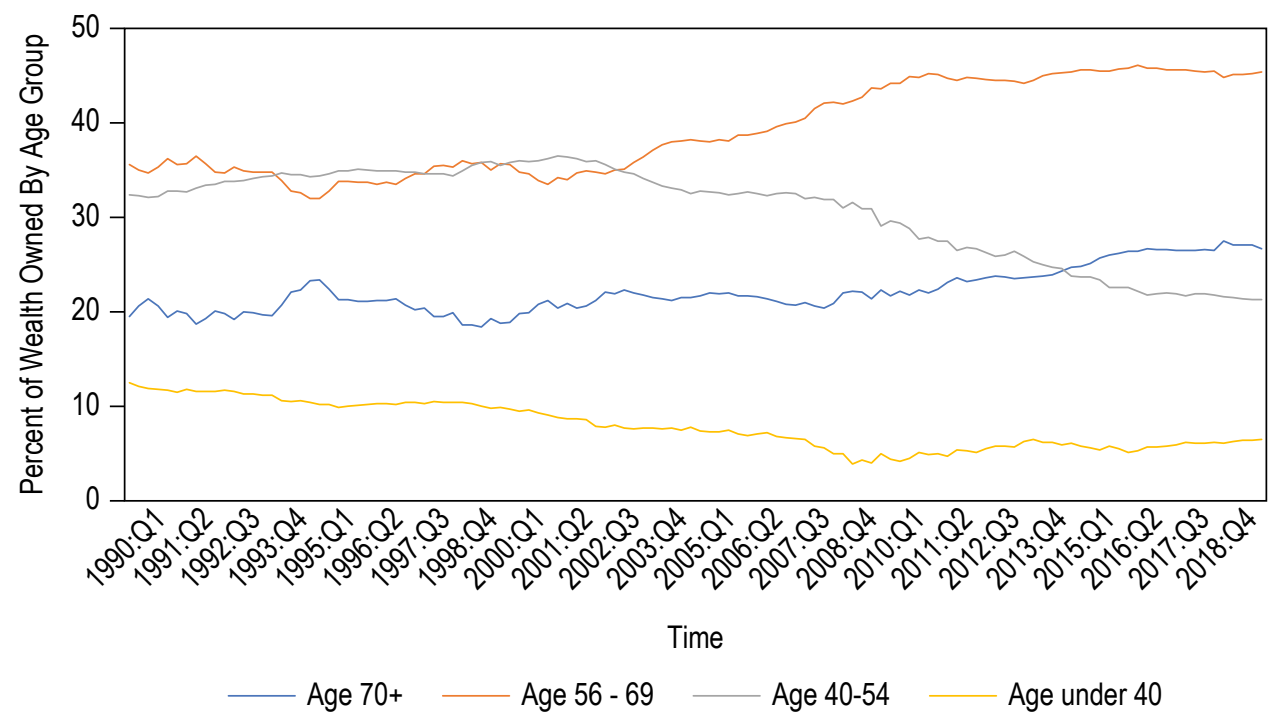

Figure 1. Share of U.S. Wealth Owned by Age Groups (Federal Reserve, 2020). The term 'Q' following the year indicates the respective quarter in a given year.

However, if we consider the trend for each age group over time, we can clearly see that millennials (who fall into the age group under 40 y.o. ${ }^{1}$ in 2018) are worse off financially than their predecessors. For example, in the first quarter of 1990, individuals who were less than 40 at that time owned $12.1 \%$ of the U.S. wealth compared to only $6.5 \%$ of U.S. wealth owned by people who were under 40 y.o. in 2018 . The same trend was observed for the age group of 56-69 y.o. indicating that more recent generations are struggling to accumulate wealth compared to their predecessors.

Table 1 shows various measures of financial condition of the age group under 40 y.o. over time. The data shows percentage of assets, liabilities and wealth owned by this age group at two points in time (1990 and 2018) and the percentage change over this time period. According to Table 1, there is clear evidence that millennials are much worse financially now than other generations were at the same age.

Share of U.S. assets owned by the age group of under 40 y.o. has dropped by $48 \%$ in the last 30 years. In addition, this age group owns less real estate and significantly lower percentage of equities and mutual funds today than the individuals in the same age category did in 1990. A similar observation can be made for the liabilities. Mortgage, however, decreased much faster than consumer credit which may imply that people in

Table 1. Comparative analysis of financial conditions of 'under 40' age group between 1990 and 2018 (Federal Reserve, 2020).

\begin{tabular}{llcl}
\hline Financial metrics & $\mathbf{1 9 9 0}(\mathbf{\%})$ & $\mathbf{2 0 1 8}(\mathbf{\%})$ & Change (\%) \\
\hline Assets & 16.8 & 8.7 & -48.2 \\
Equity and mutual funds & 11.4 & 3.5 & -69.3 \\
Real estate & 21.2 & 12.4 & -41.5 \\
Liabilities & 44.3 & 23.7 & -46.5 \\
Mortgage & 45.7 & 18.5 & -59.5 \\
Consumer credit & 46.0 & 39.8 & -13.5 \\
Wealth & 12.5 & 6.5 & -48.0 \\
\hline
\end{tabular}

\footnotetext{
${ }^{1}$ Y.o. stands for 'years old'.
} 
this age group today cannot afford home ownership, but still use consumer credit relatively extensively. Finally, the share of wealth owned by this age group today is only $6.5 \%$ compared to $12.5 \%$ owned by people younger than 40 y.o. in 1990. One may argue that those declines are associated with the changes in the population profile of the country over time. According to the U.S. Census Bureau, between 1990 and 2018, the number of people who fall in the age group of under 40 y.o. decreased only by $10 \%$, whereas the decrease across various measures of financial condition of this age group over the same time period is significantly larger as reported in Table 1. Therefore, this data provides the evidence of the continued deterioration in the financial condition of the age group under 40 y.o. which may impact millennials employees' job-hopping behavior.

Generational differences in behaviors and attitudes have been studied extensively for several decades. Numerous studies in the field of developmental psychology addressed the observed changes in attitudes and behaviors to understand if those behaviors change across the life span of an individual (e.g. Oh et al., 2020) found that individuals exhibited more empathy as they moved along the life span) or they can be attributed to a specific generation (e.g. behaviors are unique to the millennial employees only). Becton et al. (2014) found that millennial employees exhibit high job mobility behaviors and are less compliant in the workplace, and Lyons et al. (2015) found that younger generations tended to be more mobile but chose relatively similar career patens compared to their predecessors. Contrary to that, another study concluded that there was no meaningful relationship between the generation the employee belongs to and his/her work outcome, and thus suggested that the differences in their workplace behaviors were most likely attributed to other factors (Constanza et al., 2012). Therefore, while there is some conflicting evidence about the presence of generational differences in work-related behaviors, they remain important factors which would be an important addition to the future research on this topic.

\subsection{A note on employee loyalty}

Loyalty, often defined in a broad sense as an individual's commitment or attachment to someone/something, is simple to define in a general context, but is more challenging to capture in the context of organizational behavior (Stanton et al., 2003). Yousef (2001) defined loyalty as an employee's commitment to the organization's goals, values and success and defined three possible types of commitments: (1) normative commitment (dedication to the goals of the organization); (2) affective commitment (emotional attachment); and (3) continuance commitment (willingness to remain in the company for a prolonged period of time). According to a survey of the employee loyalty in the Middle East and North Africa, $30.3 \%$ of respondents defined loyalty as willingness to be dedicated to the employer and abide by the rules of the organization, $25.3 \%$ equated loyalty with eagerness to take on initiatives and promote company's vision, and only $11.1 \%$ associated retention rates with the employee loyalty (Aliawamis, 2016). Therefore, based on the theoretical and empirical evidence on definition of loyalty, employee loyalty should not be measured solely by the continuity of employment. However, length of employment (years worked for the employer) can serve as a proxy for the continuance commitment and thus can be indicative of the employee loyalty when considered in combination with other factors. The results of this study are not sufficient to draw conclusions about employee loyalty, but they can serve as one of several factors that help determine the loyalty.

\subsection{Objectives}

The objectives of this paper are threefold: (1) to conduct a national-level survey and provide the assessment of current job-hopping trends among millennial employees in the U.S. food and agribusiness sector; (2) identify job-related factors influencing millennial employees' decision to stay with their current employer; and (3) to evaluate how job-related and demographic factors impact the frequency of job-hopping among millennial employees'. The paper also discusses implications of the findings of this research for employers and suggests potential initiatives that might reduce the degree of job-hopping in the U.S. food and agribusiness sector. 


\section{Methods}

\subsection{Survey instrument and data}

The study uses primary data from a national-level survey conducted by the authors of the paper between February and May of 2018. The researchers employed an online survey instrument and surveyed millennial employees with five to ten years of work experience in the U.S. food and agribusiness sector.

Online surveys have gained popularity among social scientists and market researchers over the last decade as more individuals gained access to the internet (PewResearch Center, n.d.). Advantages of online surveys include low cost, shorter data collection period, greater convenience for the responder, and lower social desirability bias (Bethlehem and Biffignandi, 2012; Dillman, 2006; PewResearch Center, n.d.). However, the key methodological issues of online surveys are the non-response and absence of a systematic way for random sampling of the general population (Vehovar and Manfreda, 2008). As suggested by Vehovar and Manfreda (2008), sending a follow-up email to respondents and keeping the questionnaire short, to the point and simple can improve the response rate.

AgCareers.com and Agriculture Future of America (AFA) served as industry partners and helped administer the survey. First, they used their national email listserv of clients/members/subscribers to identify those who meet the criteria of interest in this study. Second, they disseminated the survey by sending an email with a link to the survey to qualifying members and posted it on their social media channels. Finally, they sent out two reminders via email and/or social media to encourage participation in the survey.

Two alternative approaches to data collection - revealed versus stated preferences - were considered when determining the correct methodological approach for this study. The data collected through revealed preferences framework can ensure a higher accuracy of findings but is more costly and time-consuming as it requires a more-involving methodology (an experiment design rather than a survey instrument). This study was motivated by our discussion with industry stakeholders about the millennial employees and employers' desire to understand this population group better; in particular, how their perception of certain job-related factors impact the frequency of job-hopping. Thus, despite some limitations of the stated preferences framework, this approach seems feasible and appropriate to achieve the goal of this study.

The perception type questions have been used recently in the brand perception research in the marketing field to understand how a certain brand is viewed by customers, employees and other stakeholders (Qualtrics, 2020). Thus, this framework was adopted to help employers better understand what their employees valued about the company/organization they worked for and how those attitudes impacted job-hopping. Qualtrics Survey Platform was used to create the questionnaire and record the responses. The questionnaire consisted of 35 questions (Likert-type, rank order, open-ended and rating scale types) that covered the following areas: (1) demographics; (2) employment history; (3) overall satisfaction with current employer; (4) perception of importance of various work-related factors on millennials' decision to stay with the employer.

The survey instrument was reviewed and tested by several third-party stakeholders (e.g. AgCareers.com, AFA). Authors have followed up with their contacts at these two organizations to receive their feedback on the instrument and discuss any potential pitfalls with the survey twice during this process. The survey was sent out to 4,000 individuals and had a $7.9 \%$ response (316 responses) and an $83.3 \%$ completion (263 completed responses) rates. 53 responses were dropped from the survey due to partial completion or the fact that the employee did not hold a full-time position at the time of the survey. 


\subsection{Statistical analysis}

First, the descriptive analysis of the survey data was conducted using various descriptive statistics (including frequency and percentage analysis for categorical variables). This step of the analysis helped accomplish objectives 1 and 2 of the study. Then, the Poisson regression model with stepwise variable selection was used to identify the factors that seem to affect millennials' job-hopping behavior based on the survey data. Stepwise regression was selected as an appropriate statistical technique to identify the statistically significant relationships between variables. In addition, factor analysis was conducted to identify the important factors that should be included in the model and which would represent each cluster of factors (e.g. company cluster, work environment cluster, and benefits cluster) as a robustness check to validate the choice of variables included in the model. The results obtained were in line with the findings from our original approach using a stepwise regression model.

Number of employers that millennials had during their career was used as a dependent variable in this study. This variable was tested for normality using the Shapiro-Wilk test. This test rejected the null hypothesis that the data came from normal distribution with $P$-value less than 0.01 . QQ plot also revealed lack of normality in the data. Histogram and summary statistics of the dependent variable suggest that the dependent variable follows a Poisson distribution. More formally, Pearson Chi Squared goodness of fit test demonstrated that we failed to reject the null hypothesis that data came from Poisson distribution with a $P$-value of 0.8983 , which supports the choice of the Poisson distribution for the dependent variable. Thus, the Poisson regression model is the most appropriate type of generalized linear model for our analysis. Stepwise variable selection using BIC criterion was chosen to identify the variables that should be retained in the final model. R software was used to perform the analysis (R Foundation for Statistical Computing, Vienna, Austria).

\section{Results}

The first part of the results section highlights the findings of the survey on employee demographics, their job satisfaction and job-hopping trends. The second part explains the job-related factors influencing millennial employees' decisions to stay with their current employer. The remaining part of this section presents results of the statistical analysis that estimates the impact of job-related and demographic factors on the frequency of job-hopping among millennials. Since this survey is likely to have sampling bias and therefore is not necessarily representative of the overall population of interest, its results cannot be generalized to a population of millennial employees with five to ten years of work experience in the U.S. food and agribusiness sector. The results of this study should therefore be interpreted as perceptions of those respondents who were a part of the surveyed sample. Even though results cannot be generalized to the overall population, the findings can potentially provide some insights for employers in the agribusiness industry.

\subsection{Demographics}

In the sample studied, both genders were relatively evenly represented: $56 \%$ of respondents are women, $44 \%$ men. The age of millennial employees ranges from 20 to 37 years (based on the definition of millennial demographic group adopted by Pews' research). In this study, the average age is 26.3 years; however, the distribution of respondents by age is skewed right. About $80 \%$ of respondents are of age 24 through $31,10 \%$ are 22 or less, and $10 \%$ are 32 to 37 years old as depicted in Figure 2.

This survey attempted to target only millennials who have held or currently hold a full-time professional job ${ }^{2}$. Results indicate that the respondents indeed match the specification of our target group: $73 \%$ of respondents have Bachelor's degree, $19 \%$ hold other advanced degree, and $94 \%$ are currently employed ${ }^{3}$. Majority of

\footnotetext{
${ }^{2}$ As defined in the survey, the job that requires a special education, training or skills (Merriam Webster Dictionary, 2017; https://www.merriamwebster.com/dictionary/professional). The employment, however, does not have to be in the area in which the individual obtained their education. For example, agronomy sales, crop scout jobs, etc.

${ }^{3}$ The remaining $6 \%$ are not currently employed but have had a professional job in the past.
} 


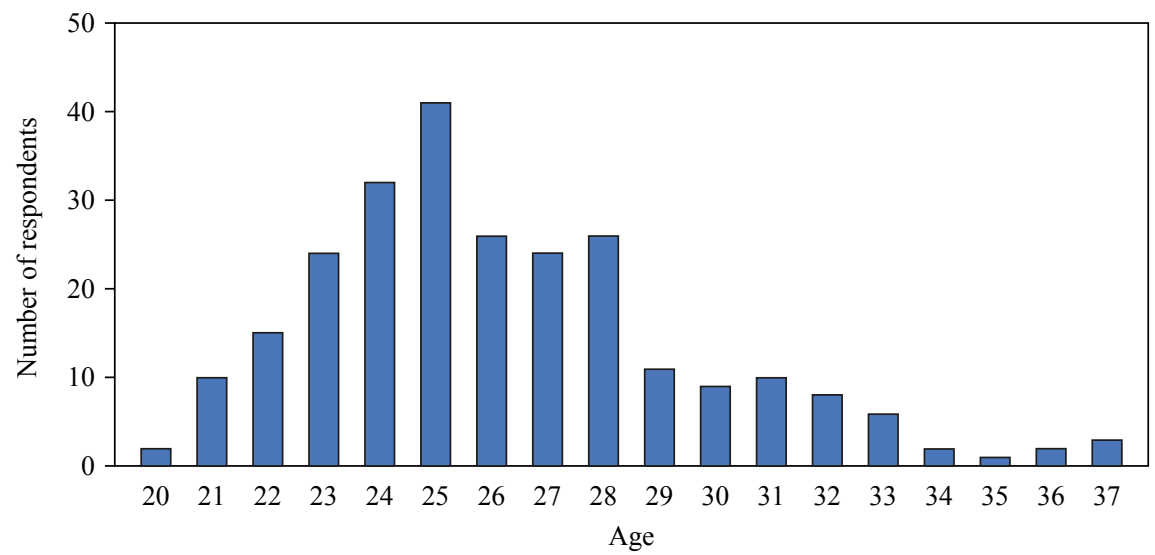

Figure 2. Distribution of respondents by age.

respondents are salaried employees (65\%) working in an intermediate $(56 \%)$ or upper management $(11 \%)$ positions.

Figure 3 shows that respondents represent various areas of the food and agribusiness sector fairly equally from input to processing/merchandising segments (e.g. crop, livestock production, chemical, food products and processing, finance and banking, etc.). Given a relatively large size of the category 'other', these responses were carefully reviewed and grouped into four main subcategories: services (e.g. legal, extension, consulting, $36.7 \%)$, production agriculture (10.2\%), supply chain/processing/marketing $(24.5 \%)$, input sector $(20.4 \%)$ and research $(8.2 \%)$.

The survey instrument asked several questions regarding extracurricular activities and other experiences that may affect the employees' career expectations and loyalty to the employer. $52 \%$ of respondents indicated that they had been involved with at least one student professional organization while pursuing their degree, and about half of these individuals had been involved at least in two of those organizations.

The overwhelming majority of respondents $(82 \%)$ had either direct or indirect exposure to agriculture prior to getting a professional full-time job in this field. $51 \%$ of individuals grew up on a farm, whereas $38 \%$ had some other indirect exposure to agriculture (e.g. worked on a farm, did internship in this field, etc.). Finally, only slightly more than a third of all respondents $(35 \%)$ have had an international and/or cultural immersion experience such as study/work/internship abroad, etc.

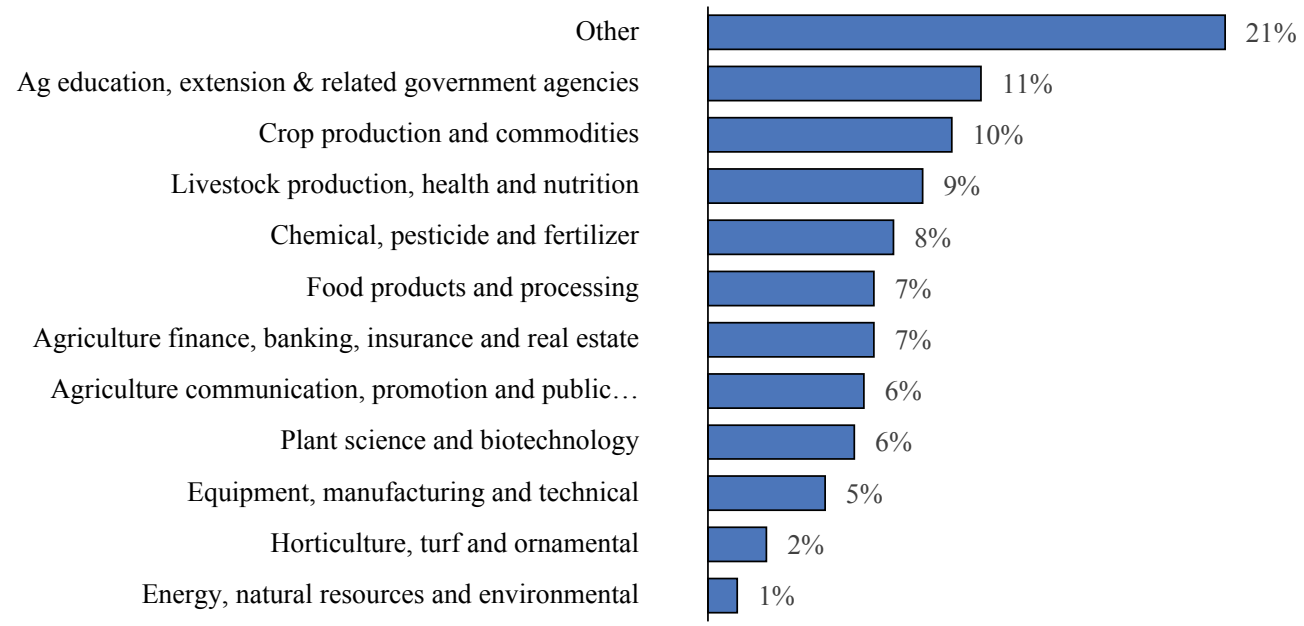

Figure 3. Industry representation by respondents. 


\subsection{Job-hopping trends and job satisfaction}

As part of the survey, employees were asked to self-report the degree of their satisfaction with their current employer using two questions: first, they were asked to rate their satisfaction with their current job, and the follow up question asked if they believed they needed to switch their current employer sometime in the future to achieve their career goals. Results show that $70 \%$ are either very satisfied or satisfied, whereas a little over a third of respondents are either dissatisfied or in limbo.

Figure 4 reveals another interesting observation: only about a third (29\%) of respondents believe they do not need to change their current job to achieve their career goals, and 51\% are confident the change is needed. Two important observations are noted here: (1) almost every third employee in the survey is not currently satisfied with their employer which may lead to detrimental consequences for employers; and (2) while only a third of respondents stated they were not satisfied with their current job, significantly more of them (51\%) believed they would need to change their current job to achieve long-term career goals. The latter observation may indicate that the frequency of millennial employees' job-hopping may be a function of not only current job satisfaction, but also the ability to achieve long-term career goals.

The surveyed instrument studied the job-hopping behavior from three different angles: (1) how many jobs employees have already had in the past and how frequently they switched them; (2) employment continuity with their current employer; and (3) how many more employers they plan to have in the future. The results revealed the presence of job-hopping in the U.S. food and agribusiness sector: on average, respondents have had 2.3 jobs already in their early career. The distribution of results shows that $31 \%$ of respondents have already had at least three full-time professional jobs so far. Given that the average age of the respondent in this study is 26 , the results suggest that millennial employees surveyed in this study switch jobs every two and a half years which indicates the presence of an acute job-hopping among millennial employees. Respondents were also asked to report the number of years they worked in each of their previous professional positions for the last four employers ranked from the most recent (on the left) to the least recent (on the right) employers. Figure 5 shows a series of histograms that help understand job-hopping trends over time. Each graph shows the distribution of respondents by the employment continuity (length of time worked for a particular employer). For example, $62 \%$ of the respondents worked for their previous (most recent) employer for two years or less.

There are two observations that are worthwhile to note from these histograms: (1) each distribution is right-skewed indicating that majority of employees stayed with each of the specified employers for a short period of time (three years or less), and thus the job-hopping is indeed present in the U.S. food and agribusiness sector; and (2) a small shift in the weight of the distribution to the left was observed over time (from the least recent to the most recent employer) indicating that individuals may indeed job-hop more earlier in their careers before they find the right fit and/or gain the necessary background and experience.

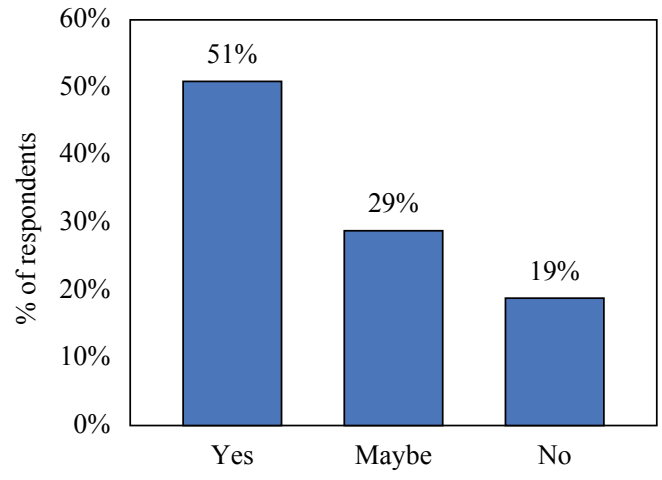

Figure 4. Response to the question: 'Do you need to change your current employer to meet career expectations?' 

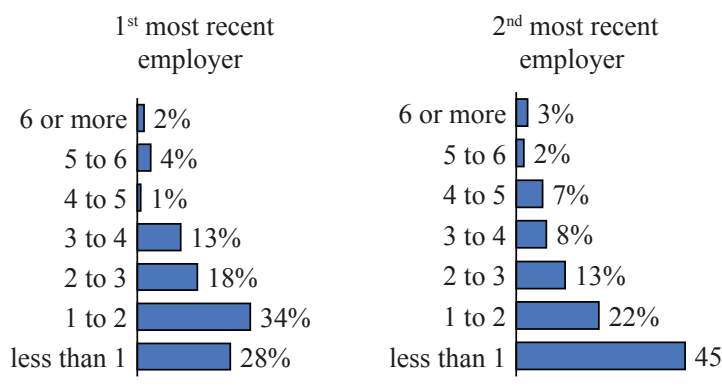

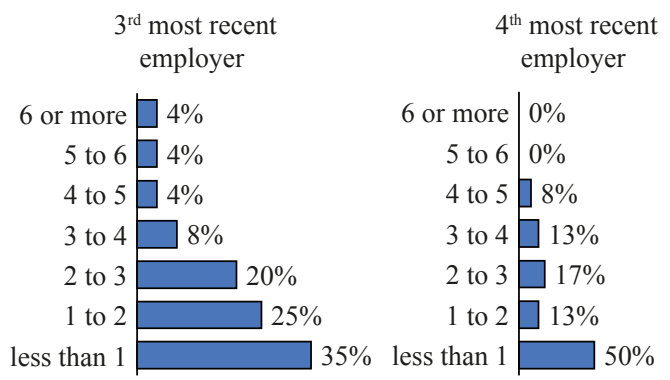

Figure 5. Employment continuity: years worked for each of the previous employers.

Given the information obtained through the survey in this study, it is impossible to determine and isolate the exact reason why a significant percentage of employees do not work for the same employer for more than a year. However, the series of distributions in Figure 6 show that the respondents tend to stay with their employers longer as they progress in their careers.

The results also suggest that job-hopping is not only the trend of the past, but it is expected to remain at least in the near future. Slightly over half of respondents (53\%) have worked for their current employer for two years or less, and $41 \%$ of respondents plan to leave their current employer in three years or earlier. Figure 7 shows that only $29 \%$ of respondents plan to stay with their current employer beyond five years. Therefore, these results suggest that employers will indeed face low employee retention in the near future as they are likely to lose $30 \%$ of their millennial employees in the next three years.

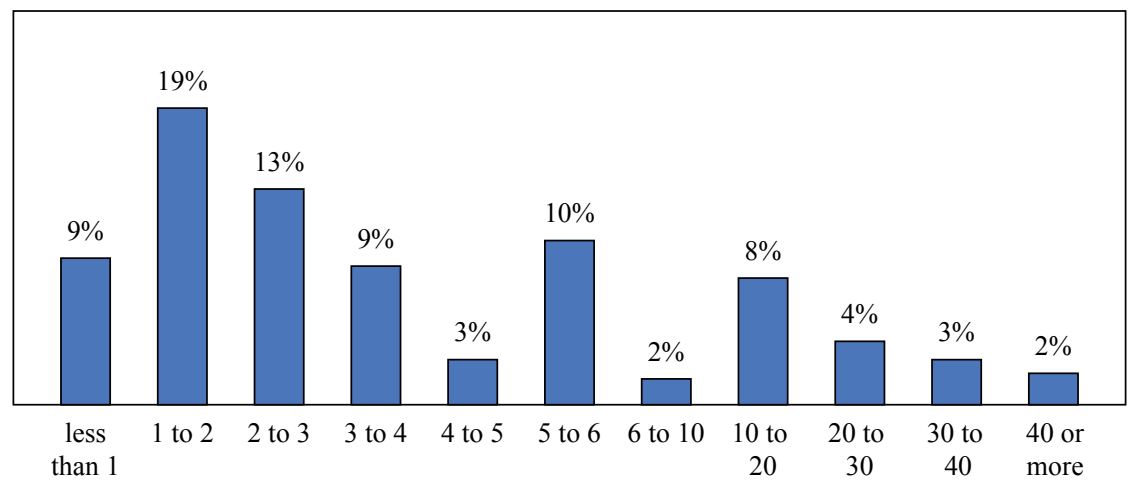

Figure 6. Number of years employees plan to stay with their current employer.

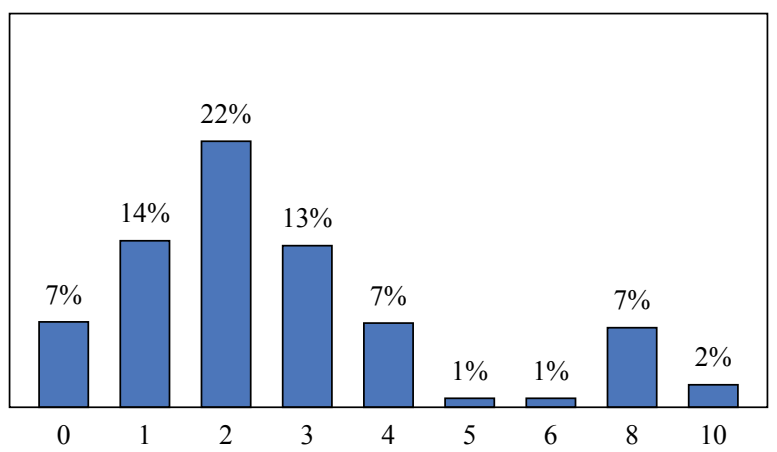

Figure 7. Number of employers expected to have in the future. 
However, when asked how many more employers millennials anticipated to have in the future, the majority indicated they did not plan to job-hop as much as they did before. $7 \%$ of respondents did not think they would have any more employers, $49 \%$ planned to have another one to three employers, and $18 \%$ planned to have four or more jobs (20\% did not respond). While these results are not sufficient to draw strong conclusions, they suggest that the job-hopping trend may slow down in the future as this generation of employees gains experience and is able to find the job that allows them to meet their career goals. In particular, these results show that slightly over a half of employees will work on average 15 years for each of their employers in the future (given the average age of respondent in the study and assuming a retirement age of 65).

The next set of questions asked employees to self-report/state potential reasons for considering leaving their current employer. All respondents were split into two subsamples for the purpose of this question: (1) respondents who believe they need to leave their current employer to meet career goals; and (2) respondents who do not think they need to leave their current job to meet their career goals. Both subsamples were instructed to select the most important reason why they are considering leaving their current employer (for subsample 1) or would have considered to leave their current employer for another employer (for subsample 2 ). The most frequent reason selected by the subsample 1 was the lack of opportunities for professional growth and development offered by their current employer. Subsample 2 said they would have considered leaving their current employer for another employer if the latter offered better opportunities for professional growth and development.

Therefore, the results suggest that even though the majority of millennial employees seem to be happy in their current jobs (over 70\%), 51\% know they need to change their current job to achieve their long-term goal and $40 \%$ plan to leave their current employer in three years or earlier. Given the reasons they stated for leaving or potentially leaving the employer, these results suggest that the increase in job-hopping may be a result of millennials' clear set career goals (which require professional development and growth) and not their impatience or reasons found through anecdotal evidence. Therefore, they may be enjoying the culture and work they do; however, they will start looking for another employment opportunity within the next three years if their current employer does not provide opportunities to grow professionally.

\subsection{To stay or not to stay: job-related factors that matter to millennials}

A survey includes a set of questions to understand what job-related factors millennials value the most when deciding whether to stay with the company. These insights will help employers understand what factors they may need to explore further to enhance millennial employee retention. Employees were asked to rank the importance of various factors pertaining to: (1) the company; (2) the work environment; and (3) employee benefits offered in today's workplace on their decision to stay with the employer. The visual representation of results is presented in the Supplementary material.

Among all factors related to company's performance, the top three most important factors selected by respondents are the organization integrity, strategic direction, and overall reputation of the company. Unlike in non-agriculture fields, only $56 \%$ of millennial employees in the food and agriculture industry considered social responsibility of the company as a very important or extremely important factor. Also, $58 \%$ of respondents ranked financial performance of the company as an extremely or very important factor in their decision to stay with their employer.

As for the factors related to the work environment, healthy work-life balance, good relationship with management, and stimulating environment were ranked as extremely and very important factors by 84 , 83 and $82 \%$ of the respondents respectively. Good relationships with coworkers were also ranked high (fifth most important factor), but it is important to keep in mind that good relationships with management were ranked higher than good relationships with co-workers. Significantly lower percentage of respondents ranked frequent feedback and fun work environment as extremely and very important factors (59 and 56\% respectively). 
In the area of employee benefits, health care benefits and amount of paid leave were ranked as the top two most important factors impacting millennial employees' decisions to stay with the employer or leave. These results also support findings of other studies. However, unlike other industries, only $28 \%$ of respondents considered time off to do volunteering as an important factor determining their loyalty to their employer.

Considering factors across all three groups (company, work environment and benefits), work-life balance, relationship with management, health care benefits, environment, and strong organizational integrity are factors millennials value the most when deciding to stay with the same company.

\subsection{Effect of job-related and demographic factors on frequency of job-hopping}

The following section provides and interprets results of the Poisson regression model analysis. The stepwise variable selection identified eight independent variables to be used in the Poisson regression model (Table 2).

The number of employers the respondents have already had in their career was used as a dependent variable in the model as an indication of the frequency of job-hopping. Due to the stepwise selection technique used, all variables in the model are statistically significant at 1 or $10 \%$ level. Factor analysis was conducted in addition to the stepwise regression technique to identify the important factors that should be included in the model and which would represent each group of factors (e.g. company-related, work environment-related and benefits-related) as a robustness check to validate the choice of variables included in the model. The results obtained were in line with the findings from our original approach using a stepwise regression model.

When interpreting the coefficients in the model, it is important to remember that these independent variables reflect the perceived importance of certain job-related factors (e.g. how important the frequent feedback is to millennial employees when deciding if they should stay with the same employer) rather than the indicator of the actual presence/absence of these factors in their current/previous employment.

From the first glance, positive signs of estimates on the gender and age variables seem to follow the logic and are in line with the anticipated results: men tend to job-hop more than women, and given a relatively narrow age range of respondents as defined by the study, employees seem to continue job-hopping within this age group until they gain experience and find the right fit. One potential explanation of positive signs of the coefficients corresponding to the environment fostering innovative thinking and frequent feedback is that these employees value innovation in the company and frequent feedback but are not receiving/ experiencing them, and therefore, they leave their current employer and continue job-hopping. While the

Table 2. Poisson regression model estimates of major factors influencing job-hopping by millennial employees. ${ }^{1}$

\begin{tabular}{lclr}
\hline Dependent variable: number of employers & Estimates & $\begin{array}{l}\text { Exponentiated } \\
\text { estimates }\end{array}$ & Change (\%) \\
\hline Intercept & $-0.7518(0.491)$ & 0.47 & -53 \\
Environment fostering innovative thinking & $0.2067^{* * *}(0.061)$ & 1.23 & 23 \\
Opportunities to take on varied roles & $-0.1637^{* * *}(0.060)$ & 0.85 & -15 \\
Provides more frequent feedback & $0.0435^{*}(0.022)$ & 1.04 & 4 \\
Collaborative work environment & $-0.1029^{*}(0.053)$ & 0.9 & -10 \\
Flexible role- employees can define their job duties & $0.0732^{*}(0.043)$ & 1.08 & 8 \\
Gender (male) & $0.1582^{*}(0.093)$ & 1.17 & 17 \\
Age & $0.0546^{* * *}(0.013)$ & 1.06 & 6 \\
Salaried employee (yes) & $-0.303^{* * *}(0.096)$ & 0.74 & -26 \\
Observations & 210 & & \\
AIC & 681 & & \\
\hline
\end{tabular}

$1 * * * P<0.01, * * P<0.05, * P<0.1$; values between parentheses are standard errors. 
analysis conducted in this study cannot provide research evidence for this hypothesis, authors believe they may be individuals who are likely to be 'seekers of the perfect fit from outside' - high achievers, who do not settle unless they find the ideal job, and if not satisfied with the current job, they seek for growth from outside (that is look for another job that fits their skills and expectations).

The negative sign on the coefficients reflecting the collaborative environment and ability to take on varied roles within the organization indicate that those employees who value these factors highly tend to stay with the same employer longer. One potential explanation of this sign is that these are individuals who may be 'seekers of growth from within'. They tend to job-hop within the organization and do not switch employers frequently. They prefer to grow from within the organization (that is to try identifying the best fit within the company, not outside).

Given the analysis that was conducted in this study, no further insights on the direction of the relationship between the dependent and independent variables in this model can be made with sufficient justification or support and thus require further study and investigation. However, these findings shed light on potentially very important observations that need to be tested using other research methods. Therefore, consequent discussions constitute authors' hypotheses and will serve as a foundation for further research.

\section{Discussion and conclusions}

By 2025, millennials will constitute approximately $40 \%$ of the U.S. workforce (Asghar, 2014). The existing research suggests that only $18 \%$ of surveyed millennials plan to stay with the same employer long term, and $60 \%$ of millennials leave their employer within three years from their start date (PwC, 2011; Schawbel, 2013). The U.S. food and agribusiness sector is not an exception: in addition to the potential presence of job-hopping, the sector is also facing a higher demand for talent as the growing global demand for food and fiber increases. Therefore, in this study, a nation-wide survey of millennial employees who work in food and agribusiness sector was conducted to: (1) identify the degree of job-hopping in the food and agribusiness sector; (2) identify job-related factors influencing their decision to stay with their current employer; and (3) evaluate how these perceived factors impact their frequency of job-hopping.

Our findings indicate that the job-hopping is also observed in the food and agribusiness sector but to a lesser degree compared to the non-agriculture sectors. On average, the respondents have had 2.27 jobs in their early career, about $31 \%$ have already had at least three full-time professional jobs, and $40 \%$ plan to leave their current employer within the next three years (compared to $60 \%$ in the non-agriculture sectors). Only $30 \%$ of respondents indicated that they were not satisfied in their current job, but $71 \%$ stated that they needed to change their current employer to achieve their long-term career goals. Since this survey is not reflective of the overall population, its results cannot be generalized and should be interpreted as perceptions of those individuals who responded to the survey. Even though results cannot be generalized to the overall population due to likely sampling bias, our findings can provide some insights for employers in the agribusiness industry. These results indicate that employers in the food and agriculture industry need to recognize the presence of this job-hopping and its potential implications.

When asked to rank the importance of various factors related to the company's performance on their decision to stay with the company, the respondents ranked organization integrity $(82 \%$ of respondents ranked it as extremely important and very important factor) and strategic direction (74\%) as two most crucial factors. In the work environment group of factors, they stated healthy work-life balance (84\%), good relationship with management (84\%) and stimulating environment (82\%) as most important factors impacting their decision to stay or leave. Health-care benefits $(82 \%)$ and amount of paid leave $(80 \%)$ were the top two factors in the benefits group of factors. Finally, the number one reason for leaving or considering leaving their current employer was the lack of opportunities for career growth and advancement. These findings show that employers need to focus on meeting the employees' not only short-term but also long-term career goals to reduce the job-hopping. Effective strategies to understand employees' long-term career goals and 
continued efforts to monitor their progress towards those goals must be developed and implemented to help reduce the job-hopping.

The results of the regression analysis allowed us to analyze the impact of employees' perception of workrelated factors on the frequency of job-hopping. Millennials who highly value opportunities to take on varied roles within the organization and seek a collaborative work environment tend to have fewer employers in their careers and thus are more loyal to their current employers. Contrary, employees who highly value the importance of working in the environment that fosters innovative thinking and who demand frequent feedback tend to have more employers in their career implying that they job-hop more.

Further research is needed to better understand some of the findings of this study. It would be beneficial to study the loyalty of millennial employees as a function of various personality types ('seekers of perfect fit from outside' versus 'seekers of growth from within') rather than just a set of factors that impact their job satisfaction. The same benefits may be perceived differently by employees with different personality types and thus, providing a one-size-fits-all solution will not be effective if implemented by employers. Thus, additional research on the personality types of employees and its impact on their job-hopping behavior may help employers develop more effective targeted strategies to enhance employment continuity among millennial employees in the U.S. food and agribusiness sector.

\section{Supplementary material}

Supplementary material can be found online at https://doi.org/10.22434/IFAMR2020.0001

Figure S1. Percentage of employees who ranked company-related factors as extremely important and very important when deciding to stay with the same employer.

Figure S2. Percentage of employees who ranked work environment-related factors as extremely important and very important when deciding to stay with the same employer.

Figure S3. Percentage of employees who ranked benefits-related factors as extremely important and very important when deciding to stay with the same employer.

Figure S4. Most and least important factors (across all groups) to millennial employees when deciding to stay with the same employer.

\section{References}

AgCareers.com. 2013. Total rewards survey report. AgCareers.com, Clinton, NC, USA. Available at: https:// www.agcareers.com/newsletters/total_rewards_survey_results_for_NL.htm

AgCareers.com. 2014. Candidate motivation and behavior in the agricultural industry. AgCareers.com, Clinton, NC, USA. Available at: https://tinyurl.com/y297afys

Agricultural Appointments. 2015. Salary and trend report. Agricultural Appointments, Sydney, Australia. Available at: https://www.agri.com.au/2015-trend-report/

Aliawamis, M. 2016. Employee loyalty in the Middle East and North Africa. Bayt.com Blog. Available at: https://www.bayt.com/en/blog/26942/bayt-com-infographic-employee-loyalty-in-the-middle-eastand-north-africa/

Asghar, R. 2014. What millennials want in the workplace (and why you should start giving it to them). Forbes, January 13. Available at: https://www.forbes.com/sites/robasghar/2014/01/13/what-millennials-wantin-the-workplace-and-why-you-should-start-giving-it-to-them/\#2cabe3df4c40

Becton, J.B., H.J. Walker and A. Jones-Farmer. 2014. Generational differences in workplace behavior. Journal of Applied Social Psychology 44: 175-189. https://doi.org/10.1111/jasp.12208

Bethlehem,, J. and S. Biffignandi. 2012. Handbook of web surveys. Wiley handbooks in survey methodology. John Wiley \& Sons, Hoboken, NJ, USA, pp. 567-573. 
Costanza, D.P., J.M. Badger, R.L. Fraser, J.B. Severt and P.A. Gade. 2012. Generational differences in work-related attitudes: a meta-analysis. Journal of Business \& Psychology 27: 375-394. https://doi. org/10.1007/s10869-012-9259-4

Deloitte. 2015. Mind the gaps: the 2015 Deloitte millennial survey. Deloitte Touche Tohmatsu, London, UK. Available at: https://www2.deloitte.com/content/dam/Deloitte/global/Documents/About-Deloitte/ gx-wef-2015-millennial-survey-executivesummary.pdf

Dillman, D. 2006. Mail and internet surveys: the tailored design method, $2^{\text {nd }}$ edition. John Wiley \& Sons, Hoboken, NJ, USA.

Federal Reserve Bank of Atlanta. 2014. The economic plight of millennials. Federal Reserve Bank of Atlanta, Atlanta, GA, USA. Available at: https://www.frbatlanta.org/-/media/documents/regional-economy/ econsouth/14q1.pdf

Federal Reserve. 2020. DFA: distributional financial accounts. Distribution of household wealth in the U.S. since 1989. Federal Reserve, Washington, DC, USA. Available at: https://www. federalreserve.gov/releases/z1/dataviz/dfa/distribute/chart/\#quarter:119;series:Consumer\%20 credit;demographic:age;population:1,3,5,7; units:shares;range:1989.3,2020.1

Global Prairie and YI Advisors. 2015. FarmNext. Giving voice to the next generation of food producers. Global Prairie, Washington, DC, USA. Available at: https:/www.globalprairie.com/our-work/farm-next

Goecher, A., E. Smith, J. Fernandez, R. Ali and R. Theller. 2015. Employment opportunities for college graduates in food, agriculture, renewable natural resources, and the environment. United States, 2015-2020. USDA, Washington, DC, USA. Available at: https://www.purdue.edu/usda/employment/

Huddle. 2013. State of the enterprise information landscape study. A Huddle report on the fragmentation of the enterprise brain. Huddle, London, UK. Available at: https://www.huddle.com/sites/default/files/ white-papers-files/Huddle_study_-_State_of_the_enterprise_information_landscape.pdf

Kronos. 2016. Motivating millennials: managing tomorrow's workforce today. Kronos, Macquarie Park, Australia. Available at: https://www.kronos.com.au/resources/motivating-millennialsreport?fs $=200 \&$ at $=$ g

Lyons, S.T., L. Schweitzer and E.S. Ng. 2015. How have careers changed? An investigation of changing career patterns across four generations. Journal of Managerial Psychology 30(1): 8-21. https://doi. org/10.1108/JMP-07-2014-02

McCrindle. 2016. Millennials in the workplace. The McCrindle Blog. Available at: http://mccrindle.com. au/the-mccrindle-blog/millennials-in-the-workplace

Mitchell, A. n.d. The rise of the millennial workforce. The Wired Blog. Available at: https://www.wired.com/ insights/2013/08/the-rise-of-the-millennial-workforce/

Nielsen. 2014. Millennials - breaking the myths. Nielsen, New York, NY, USA. Available at: https://www. nielsen.com/us/en/insights/report/2014/millennials-breaking-the-myths/

Oh, J., W.J. Chopik, S. Konrath and K.J. Grimm. 2020. Longitudinal changes in empathy across the life span in six samples of human development. Social Psychological and Personality Science 11(2): 244-253.

PewResearch Center. n.d. U.S. survey research. Collecting survey data. PewResearch Center Publications, Washington, DC, USA. Available at: https://www.pewresearch.org/methods/u-s-survey-research/ collecting-survey-data/

Pricewaterhouse Coopers (PwC). 2011. Millennials at work: reshaping the workplace. Pricewaterhouse Coopers, London, UK. Available at: https://www.pwc.com/m1/en/services/consulting.html

Qualtrics. 2020. Brand perception surveys. Qualtrics, Drive Provo, UT, USA. Available at https://www. qualtrics.com/experience-management/brand/perception-surveys/

Schawbel, D. 2013. Cost of millennial retention study. Millennial Branding and Beyond.com. Available at: http://workplaceintelligence.com/cost-millennial-retention-study/

Stanton, J.M. K.R. Stam, I. Guzman and C. Caledra. 2003. Examining the linkage between organizational commitment and information security. In: SMC'03 Conference Proceedings. 2003 IEEE International Conference on Systems, Man and Cybernetics. Washington, DC, USA, pp. 2501-2506. https://doi. org/0.1109/ICSMC.2003.1244259

Vehovar, V. and L. Manfreda. 2008. Overview: online surveys. In: N. Fielding, R.M. Lee and G. Blank (eds.) The SAGE handbook of online research methods. SAGE, London, UK, pp. 177-194. 
Yousef, D.A. 2001. Islamic work ethic: a moderator between organizational commitment and job satisfaction in a cross-cultural context. Personnel Review 152-169. 